\title{
JOB CRAFTING AND WELL-BEING IN ELDERLY CARE SECTOR: THE EFFECT OF OVER- COMMITMENT
}

Purpose: This research analyzes the moderation effect of over-commitment in the job crafting - wellbeing -relationship, in the elderly care sector in Spain.

Design/methodology/approach A cross-sectional design was implemented and a final sample of 353 participants were assessed using the Job Crafting Questionnaire, an adaptation of the Over-commitment Scale from the ERI-Q, and the General Health Questionnaire (GHQ-12).

Findings: A positive interaction between relational and task crafting and over-commitment is observed in the prediction of well-being levels. Specifically, the effect of over-commitment in the task crafting well-being relationship proved to be statistically significant when opposed to low, medium and high levels of over-commitment. Additionally, the effect of over-commitment in the relational crafting well-being relationship proved to be statistically significant only when opposed to medium and high levels of over-commitment. Finally, a direct and simple effect was observed between cognitive crafting and well-being, not moderated by over-commitment.

Research limitations/implications: Implementation of non-behavioral measurements, and a nonlongitudinal design are suggested. The development of behavioral measures for job crafting is encouraged, along with the implementation of longitudinal designs sensitive to changes in overcommitment. Possible over-commitment results are biased by an economically contracted environment. Practical implications: Job crafting training, over-commitment early detection, and further research on job crafting strategies' preferences, are suggested.

Originality/value: The moderating role of over-commitment in the job crafting - well-being relationship in the elderly care sector represents one of these attempts to better understand evidences of how work-related efforts modify a worker's psychological functioning and adaptation, reason why, specially in contexts of uncertainty, its study becomes relevant.

Keywords: job crafting, elderly care sector, nursing home employees, over-commitment, well-being. Paper type: Research paper.

How to cite: Romeo, M., Yepes-Baldó, M., Piñeiro, M., Westerberg, K. and Nordin, M. (2019). Job crafting and well-being in the elderly care sector: the effect of over-commitment. Employee Relations, 41(3), 405419. https://doi.org/10.1108/ER-04-2018-0117 
The consequences of the severe economic contraction faced during the last decade in Spain, lead to a 27.2\% unemployment rate in 2013 (Córdoba-Doña et al., 2016; Fernández-López et al., 2005; Urbanos-Garrido and Lopez-Valcarcel, 2014), and 16.74\% (3.796.100 still unemployed) in the first quarter of 2018 (Instituto Nacional de Estadística, 2018). A seriously hit sector has been that one of elderly care, with an incomitant growth of personnel to match the ageing population and growing numbers of senior citizens located in nursing homes (Associació Catalana de Recursos Assistencials ACRA, 2014; Fernández-López et al., 2005; Yepes-Baldó et al., 2016), leading to reductions in workers' perceived well-being and mental health (Kiefer et al., 2014; Peiró et al., 2014; Urbanos-Garrido and Lopez-Valcarcel, 2014).

This deterioration, specially over vulnerable groups (mid-level educated, female individuals, ages spanning 30 to 35 years old, and single citizens) (László et al., 2010) has demanded attention (CórdobaDoña et al., 2016); over-commitment, an impaired detachment from work, with the need of recovering control and assuring a job position despite low rewards (Siegrist, 1996; Siegrist and Li, 2016), has appeared as a variable of interest.

Over-commitment is defined as "a set of attitudes, behaviours and emotions that reflect excessive striving in combination with a strong desire of being approved and esteemed"' (Siegrist, 2001, p. 55), and as a susceptibility to stress "expected among persons who exhibit a specific pattern of coping with demanding situations characterized by excessive engagement and a desire of being in control" (Siegrist and Li, 2016, p. 2).

From the Effort-Reward Imbalance Model (ERI) (Siegrist, 1996), reasons why workers could enact over-commitment behaviors include the perception that received rewards (specially in terms of salary, esteem and career opportunities) fail to meet the magnitude of the deployed efforts; higher needs of control generate higher levels of compensatory behaviors, being over-commitment one of them, as a proactive exit to reduce this imbalance (Chung et al., 2015; Siegrist, 1996; Siegrist \& Li, 2016). Therefore, overcommitment is framed as a dysfunctional coping strategy (Lehr et al., 2010), as a personality characteristic, and as person-specific intrinsic component (Van Vegchel et al., 2005), that depends on individuals and 
varies according to personal evaluations in front of contextual settings.

Siegrist (1996), had already addressed this condition in the beginning of the proposal of this phenomenon by indicating that individuals with excessive needs of control could deploy coping mechanisms that demand a high amount of energy and job involvement. In this context, it could be "some conceptual overlap between over-commitment and involvement in that both represent a profound identification with the job and an internal drive to work excessively (Siegrist, 2001)" (Kinman, 2016, p. 508). Other authors pointed out its conceptual convergence with other constructs as workaholism (Rennesund and Saksvik, 2010).

Contextual conditions, such as economic downturns, have been found to be predictive of overcommitment (Lunau et al., 2013), and workers may even voluntarily submit themselves to high effort-low reward conditions to assure job stability (Chen, 2016; Fernández-López et al., 2005; Siegrist et al., 2004; Topa et al., 2016). Seen in this way, over-commitment becomes of interest to understand how current coping of workers occurs, receving attention as an independent risk factor (outside the original effort-reward imbalance Model), given its known consequences and its individualistic condition as a coping mechanism (Chen, 2016; Kinman and Jones, 2008; Philp et al., 2012).

Nevertheless, the role of how over-commitment interplays with related phenomena remains unclear in front the existent turbulent environmental settings (Siegrist and Li, 2016; Van Vegchel et al., 2005). Even more, in terms of consequences and implications, the effects of its moderating role have stumbled through literature, primarily through inconsistencies in the understanding of how a diminish of well-being is generated (Topa et al., 2016). This idea has fostered interest in the over-commitment concept, gaining attention and further investigation over how tolerance to uncertainty affects manners in which a worker interacts with the work role (Siegrist and Li, 2016; Van Vegchel et al., 2005).

In this context, deeper approaches to the patterns in which the current employee faces work will contribute to a better understanding of how this uncertainty shapes the experience of labor, and what psychology could offer in order to facilitate employee satisfaction in economic contraction settings (Córdoba-Doña et al., 2016). The moderating role of over-commitment in the job crafting - well-being 
relationship in the elderly care sector represents one of these attempts to better understand evidence of how work-related efforts modify a worker's psychological functioning and adaptation, and why, specially in contexts of uncertainty, its study becomes of relevant.

\section{Theoretical framework.}

As an answer to new trends in work figures and understanding what a worker positively interacts with their job, job crafting emerges as a strategy for the leverage of work meaning and identity. This theoretical approach highlights the employee's autonomous capabilities as a facilitator of the occurrence of personal development during labour, embracing advocacy for the understanding and promotion of well-being within the workplace that the positive organizational psychology paradigm suggests (Wrzesniewski \& Dutton, 2001; Wrzesniewski et al., 2013). Job crafting has been defined as the "physical and cognitive changes individuals make in the task or relational boundaries of their work" (Wrzesniewski and Dutton, 2001, p. 179).

Wrzesniewski and Dutton (2001), Berg et al. (2008), and Wrzesniewski et al. (2010), specify three kinds of job crafting: task crafting, relational crafting and cognitive crafting. Task crafting "involves employees actively molding the tasks they have to fulfill at work by taking on more or fewer tasks, by altering the scope of the tasks, and by changing the means of task accomplishment" (Niessen et al., 2016, p. 1289). Relational crafting comprises "changes of the quality and/or amount of interactions with others at work. Employees decide upon who they will interact with, more or less intensively while doing the job" (Niessen et al., 2016, p. 1289). Finally, cognitive crafting refers to "how employees perceive their job and altering their cognitive representation of the job" (Niessen et al., 2016, p. 1289).

In recent years, the interest in this variable has increased. It provides the possibility to know how the job crafting approach beings a proactive behavior to well-being when face with current higher demands (Berg et al., 2013), including retirement at a later age, dedication to undesired jobs for larger spans of time, and the 2008 economic recession (Demerouti and Bakker, 2014; Ghitulescu, 2006; Lu et al., 2014; Petrou, Demerouti and Schaufeli, 2016; Petrou, Demerouti and Xanthopoulou, 2016; Tims et al., 2013).

Higher levels of job crafting predict increased levels of well-being (Bakker, 2015; Bakker and Costa, 
2014; Berg et al., 2010; Ghitulescu, 2006; Siegrist and Li, 2016; Tims et al., 2013; Wrzesniewski et al., 2013; Yepes-Baldó et al., 2016). Environments defined by autonomy and complex task demands, lead to higher positive affective answers, worker satisfaction, effectiveness, commitment and team productivity, and to decreases in absenteeism, turnover intentions (French, 2009), and perceptions of underutilization when facing unchallenging job positions (Allisey et al., 2016).

Job crafting and over-commitment, represent exemplary approaches to the understanding of how workers are coping with the post-crisis contextual level phenomena. However, some reflections can be made about the research development. On one hand, it is possible that job crafting initiatives are majorly deployed by healthy workers and not by unhealthy ones in situations of discomfort, and that a "safeguard" role has been scarcely considered (Slemp and Vella-Brodrick, 2013). Wrzesniewski et al. (2013), have argued that the cultivation of positive meaning and the identity of work has been left aside by the preference given to the understanding of organizational level implications in terms of stress and productivity.

On the other hand, Siegrist et al. (2004), specify that workers that perceive higher levels of overcommitment also indicate lower levels of perceived work well-being. Nevertheless, the impact of overcommmitment over well-being has yielded inconsistent results, depending on the methods, designs, measurements and indicators of the dependent variables selected (specially, the different indicators of wellbeing), with opposed conclusions in the significance of its effects (Siegrist and Li, 2016).

Additionally, it is important to point out that conclusions on causality orders between job crafting, well-being and over-comitment are also uncertain. Some examples could be that over-commitment moderates the effects of job crafting on well-being; or job crafting fosters the possibility of over-committing with work therefore hindering well-being; or increased/decreased levels of well-being promote/hinder the intention of workers to enrich their workspace and avoid/get involved in over- commitment.

Specifically, Van Vegchel et al. (2005), Feuerhahn et al. (2012), and Siegrist and Li (2016), have suggested the importance of studying the moderating role of over-commitment, and Yepes-Baldó et al. (2016) have recently commented on the interest of the causal order relationship between the variables. Bakker (2015) and Bakker and Costa (2014), have proposed a cyclical model with relations concomitantly 
bolstering/undermining effects between these variables that modulate levels of attrition. This proposition, however, is only theoretical, and is based on the aforementioned focus that forgets the safeguarding assertion of the phenomena.

Recent researches have deepened on the effect of over-commitment as moderator. Reimann (2016) founded that reduced levels of well-being, defined as mental health, predicted by increased levels of psychological contract breach (PCB) were recorded in presence of higher levels of over-commitment. Workers that perceive a breach in the psychological contract they establish with their supervisors or with the organizations, find it harder to detach from the conditions that hamper their mental health when operating under over-commitment. Higher mental health impairment is consequently boosted. Similarly, Huyghebaert et al. (2018) reported that higher workload predicted higher frequency of sleeping problems, a relationship seemingly boosted by the presence of higher levels of over-commitment.

In the line of these previous studies, a moderation approach in the already studied direct effect of job crafting over well-being, is fostered. In environments where job crafting is deployed as a manner to optimize labor experience, economic constraints (i.e. in sectors hit by the economic crisis such as healthcare in the Southern European region) could simultaneously facilitate over-committment coping behaviors, impacting on worker's well-being (Fernández-López et al., 2005).

Consequently, the aim of the present research is to know the impact of job crafting (its subdimensions) over well-being as moderated by over-commitment (Figure 1).

\section{FIGURE 1}

Following Allisey et al. (2016); Bakker and Costa (2014); Ghitulescu (2006); Wrzesniewski et al. (2013), and Yepes-Baldó et al. (2016), we hypothesize the direct relationship between job crafting and wellbeing:

H1.1: Increased levels of task crafting predict increased levels of well-being.

H1.2: Increased levels of cognitive crafting predict increased levels of well-being.

H1.3: Increased levels of relational crafting predict increased levels of well-being. 
Regarding the moderation effect of over-commitment in the job crafting - well-being relationship, and following Siegrist and Li (2016), Van Vegchel et al. (2005), Reimann (2016), and Huyghebaert et al. (2018), we hypothesize:

H2.1: Increased levels of well-being predicted by increased levels of task crafting will only be registered in presence of reduced levels of over-commitment.

H2.2: Increased levels of well-being predicted by increased levels of cognitive crafting will only be registered in presence of reduced levels of over-commitment.

H2.3: Increased levels of well-being predicted by increased levels of relational crafting will only be registered in presence of reduced levels of over-commitment.

\section{Method}

Participants

Four residential nursing homes for elderly people were selected, each pertaining to different Catalonian municipalities, through a cross-sectional design. Participants had to comply with: being employed in the selected institutions, not to be on leave (sick leave, maternity/paternity, etc.), be on any nursing position (managerial or operative) and agree with the informed consent.

A non-probabilistic accidental sampling was implemented, leading to 353 out of 400 (88\%) Spanish employees of the nursing homes for elderly people being selected. In Table 1 we observe that the sample is broadly defined by female employees, with a mean age of 44.62 years, working during the day shift, in operative positions (nurses), and under a permanent contract figure.

\section{TABLE 1}

Procedure

Firstly, an adaptation of the over-commitment scale to the Spanish context had to be done. A backtranslation method following the International Test Commission (2005) guidelines was undertaken (English to Spanish and then back). Experts were familiar with both languages and cultures, Spanish and English, and they had knowledge of the subject matter and of the principles of test development (Hambleton, 2004).

Participants were contacted through letters directly delivered to the residential nursing homes, and afterwards, questionnaires were distributed for data collection. Informed consent from all participants was obtained, and information about procedures, objectives, and confidentiality policies was given prior to the 
assessment. Managers and research ethics committees of all participating centers approved all procedures. Instruments.

In order to assess job crafting, a Spanish version of the Job Crafting Questionnaire $(\alpha=.851)$ (YepesBaldó et al., 2016) originally developed in English $(\alpha=.91)$ by Slemp and Vella-Brodrick (2013), and anchored in Wrzesnieswki and Dutton (2001)'s original job crafting conception, was administered. This scale is a 15-item instrument with three dimensions: task crafting ("Choose to take on additional tasks at work"), cognitive crafting ("Think about the ways in which your work positively impacts on your life"), and relational crafting ("Make friends with people at work who have similar skills or interests"). The questionnaire is a 6-point Likert-type scale that ranges from 1 (Hardly ever) to 6 (Very often).

Over-Commitment was assessed with the third sub-scale of the updated version of the EffortReward Imbalance Questionnaire (ERI-Q) (Siegrist, 1996; Siegrist, 2002; Siegrist et al., 2009; Lehr et al., 2010). It was translated from English to Spanish. This scale, with $\alpha=.79$ (Siegrist et al., 2009), evaluates the intrinsic component of the ERI model through 6 items ("People close to me say I sacrifice too much for my job"). The questionnaire is a 5-point Likert-type scale that ranges from 1 (Never) to 5 (Always).

Finally, the GHQ-12 (Goldberg, 1972), was utilized to assess well-being (Schweder et al., 2015; Yepes-Baldó et al., 2016). Following Sánchez-López and Dresch (2008), as an instrument that “can be used effectively to assess the Spanish population's overall psychological well-being and to detect non-psychotic psychiatric problems" (p. 842). The scale is considered one-dimensional, and registers a mean value of internal consistency after validations in different countries of $\alpha=.85$ (Goldberg and Williams, 1996), and of $\alpha=.86$ for the Spanish context (Rocha et al., 2011). It includes 12 items ("Have you been feeling reasonably happy recently, all things considered?"). The questionnaire is a 4-point Likert-type scale that ranges from 1 (More than usual) to 4 (Much less than usual), and higher scores indicating elevated impairment.

Data Analyses.

A confirmatory factor analysis and an analysis of internal consistency using R-Studio were undertaken to analyze the psychometric structure of the Over-commitment Scale, after being implemented in the Spanish sample. 
Descriptive statistics and analyses of simple linear regression to determine the direct effect of job crafting over well-being, were ran using SPSS - Version 23. Finally, analyses of simple moderation (including its graphs) were ran using the Hayes' PROCESS macro (Hayes, 2013), in order to know the effects of over-commitment in the job crafting - well-being relationship.

\section{Results}

Psychometric structure of the Over-Commitment Scale

Regarding evidences of validity, the CFA (testing a one-dimensional model as proposed in the ERIQuestionnaire literature), demonstrates items 1 and 4 as the poorest in terms of correlation with the latent factor. General results of the CFA demonstrate a good fit between the tested model and its theoretical description $(R M R=.046 ; S R M R=.040 ; G F I=.967 ; A G F I=.924 ; C F I=.960)$. Table 2 shows the parameter estimates.

\section{TABLE 2}

A high level of internal consistency $(\alpha=.81)$ was obtained after the calculation of a Cronbach's alpha. All 6 items were considered relevant, and improvements would have been seen only if item 1 was removed (a .01 increase). Reason why, in conjunction with the obtained information in the confirmatory factor analysis, all items were kept for further analyses.

\section{Descriptive Results}

A summary of data obtained after the administration of instruments is deployed in Table 3. Despite not registering normal distributions, Pearson correlation coefficients are reported instead of Spearman's rank-order correlations, giving reduced differences between coefficients when calculated, in conjunction with the number of participants.

\section{TABLE 3}


Cognitive crafting registered the highest rating, while relational crafting registered the lowest. In relation to well-being, high perceived levels of positive functioning by the participants can be seen. Results for over-commitment reflect medium levels of perceived over-attachment to the work role. Positive statistically significant correlation coefficients were observed amongst all measurements of job crafting, and also well-being. On the contrary, a negative statistically significant correlation was observed between well-being and over-commitment. Correlations amongst variables were as expected.

\section{Direct effect of job crafting over well-being.}

Table 4 shows the results of simple regression analyses to assess the prediction of well-being levels by job crafting. Significant regressions were found in the analysis of the direct effect of job crafting over well-being: Task crafting explained $4 \%$ of variance in well-being, with levels increasing to .086 points for each increasing point of this sub-dimension; cognitive crafting explained $5.6 \%$ of the variance in wellbeing, with levels increasing to .105 points for each increasing point of the sub-dimension; and finally, relational crafting explained $3 \%$ of variance in well-being, with levels increasing to .075 points for each increasing point of relational crafting.

\section{TABLE 4}

In general, higher levels of job crafting seemed to predict higher levels of well-being. The relational crafting sub-dimension seemed to be the least predictive of well-being, while cognitive crafting seemed to be the most predictive one; consequently, hypotheses H1.1, H1.2 and H1.3 were confirmed.

Over-commitment moderation effect on the job crafting - well-being relationship.

Over-commitment was examined as a moderator of the job crafting - well-being direct effect relationship, including its interaction terms. Results can be seen in Table 5.

\section{TABLE 5}


Statistically significant increases in the variance of well-being after the interaction between job crafting and over-commitment were obtained in task and relational crafting, while non-statistically significant changes were registered in cognitive crafting.

Task crafting and over-commitment demonstrated negative correlations with well-being, while the interaction demonstrated a positive one (Figure 2). The simple effect of over-commitment in the task crafting - well-being relationship proved to be statistically significant as opposed to low $(B=.053, p<.05)$, medium $(B=.104, p<.001)$ and high levels of over-commitment $(B=.156, p<.001)$.

\section{FIGURE 2}

Secondly, an interaction between relational crafting and over-commitment can be seen in the prediction of well-being levels. The effect of over-commitment in the relational crafting - well-being relationship proved to be statistically significant only when opposed to medium $(B=.085, p<.001)$ and high levels of over-commitment $(B=.147, p<.001)$ (Figure 3).

\section{FIGURE 3}

This buffering effect demonstrates how relational crafting effect is lessened. The non-significant effect of low levels of over-commitment in the relational crafting - well-being relationship can be seen (the slope representing the relationship with well-being tends progressively to a non-inclined trend - almost horizontal). It must be pointed out, however, that increased levels of well-being can still be predicted in presence of high levels of over-commitment, but only if relational crafting levels are high.

\section{Discussion.}

The main objective of this research was to examine the moderating effect of over-commitment in the job crafting - well-being relationship. Regarding associations amongst variables, results met findings stated by previous research, job crafting positively related to higher perceptions of well-being (Berg et al., 2010; Wrzesniewski et al., 2013; Yepes-Baldó et al., 2016), and over-commitment negatively related to it (Chen, 2016; Fernández-López et al., 2005; Siegrist and Li, 2016; Van Vegchel et al., 2005). It could be 
added that using a central conception of well-being (Peiró et al., 2014), facilitated understanding relationships through a unitary concept (Siegrist and $\mathrm{Li}, 2016$ ), an issue the well-being research community should tackle to reduce inconsistents conclusions on employees' work-related health.

In order to test hypothesis 1 , simple linear regression analyses were used. Results showed that job crafting demonstrated a very low, yet significant proportion of variance explained in well-being, with cognitive crafting registering the highest amount of explained variability. These findings are quite interesting, precisely because of the registered significance, even as opposed to low levels of variance, suggesting that crafting represents a relevant strategy in the Spanish elderly care sector employees.

In this point, it is assumed that strategies that don't demand external resources could be preferred in environments of economic constriction; task and relational crafting need of other duties/coworkers, and austerity potentially decrease their availability. Also, enriching job positions with other tasks and relating with others, may not be appreciated in this sector, given protocols of action practitioners must abide by deviations (i.e., doing other activities in place of the ones every employee must perform) could potentially lead to iatrogenia. Deploying self-operational tasks as cognitive ones, could, once again, be preferred.

The previously argued possible reasons to select a specific crafting initiative could help to understand the results of the analyses to assess the moderation effects (Hypothesis 2). Despite job crafting predicting a significant variance of well-being, over-commitment played an important role in the interactions; in fact, task and relational crafting interactions became statistically significant because of their influx.

According to our results, hypotheses H2.1 was partially confirmed, while H2.2 and H2.3 were not confirmed. Specifically, over-commitment moderated the effect of task (H2.1) on well-being, but contrarily to expected, this effect can be seen on all levels of over-commitment and not only on low levels. Regarding the moderator effect of over-commitment on the relationship between relational crafting and well-being (H2.2), contrarily to expect in our hypothesis, this effect could be only seen on medium and high levels of over-commitment.

Although it could be seen as if over-commitment had a greater impact on well-being than job 
crafting, this idea loses support of the cognitive crafting interaction with over-commitment, where the change between the model without over-commitment and the model with it, was not statistically significant, despite significant effects of over-commitment influx alone. The predictive power of over-commitment, which apparently predicts most of the variability seen in well-being, gets deluded.

Recalling the fact that cognitive crafting was the highest rated initiative, it could be said that high levels of cognitive crafting seem to prevent the effect of over-commitment from generating an impact in well-being; therefore, a seemingly "safeguard" role of cognitive crafting in employees is appreciated, preventing the undermining nature of over-comittment in workers (Wrzesniewski et al., 2013).

As well, in front of low levels of over-commitment, the effect of relational crafting over well-being does not seem to be affected; probably, if higher crafting levels would have been recorded, a safeguard role could have also been seen in medium and high levels of over-commitment. It must be acknowledged, however, that this interpretation should be done under the light that over-commitment in general had an important role in the moderations, therefore, no appreciation in front of low levels could only imply a nonrelevant significance of its role, without further implications of its impact. Uncertain conclusions on this matter are acknowledged.

In general, results could support what seems to be a relevant intention of the sample to craft in work; registering the higher explained variance in cognitive crafting could reflect that independently from the contextual factors of constriction, employees are willing to craft, as French (2009) suggested. In conclusion, and for the sample of this study, job crafting accounts for a weak -yet significant- prediction of perceived levels of well-being, and increases in over-commitment seem to importantly lessen the strength of this association; however, this effect is not seen in the cognitive crafting, as it could seemingly "protect" employees' from attrition. This "protective" role seems to be better in front of increased levels of job crafting.

\section{Limitations and Recommendations.}

During the adaptation of the over-commitment scale to the Spanish context, a decision to keep the 6 original items was made, considering an observed strong correlation amongst items and the original over- 
commitment definition (Siegrist et al., 2009; Siegrist and Li, 2016), and a remotion of item 1 that would have accounted only for a marginal increase in the internal consistency coefficient and an unreasonable disruption of the total scale. Also, despite items 1 and 4 didn't contribute as expected to the general overcommitment one-dimensional model, as seen in the confirmatory factor analysis, a general fit result in the fit indexes was observed. Additionally, as stated by Macías et al. (2003), these items portray concepts of overtime, perceived in the Spanish healthcare sector as natural to healthcare jobs. Stronger evidences to keep a 6 items scale were registered than otherwise.

Secondly, it is important to point out that organizational environments are difficult to assess behavioraly and longitudinaly (disruption of activities; busier employees in the midst of economic contraction). However, measures of this kind yield more valid results, specially, of the over-commitment effects over well-being (Siegrist and Li, 2016). The development of behavioral measures for job crafting is encouraged, along implementing longitudinal designs sensitive to changes in over-commitment.

Another limitation of the study, is to analise the over-commitment within an economically restricted context, which yields knowledge of the variable only in such condition. Possible different results could be had been registered in countries out of crisis. As well, and observing the results, research on overcommitment as a stand-alone variable outside the ERI model is encouraged (Chen, 2016; Kinman and Jones, 2008; Philp et al., 2012). Over-commitment behavioral patterns could be of further salience than thought and not sufficiently studied given its consideration only as a part of the model.

Finally, further research on the preference of crafting strategies over others, including possible factors determining the selection (such as the ones argued in here, or well, cultural ones) and the use of control variables as gender, age or seniority, is encouraged.

\section{Practical implications.}

The possibility of allowing workers to develop job crafting initiatives should be highly considered by managers and organizations within the healthcare sector, especially, in contexts of economic contractions; training in these strategies is recommended as a way to protect workers from attrition, at least, in over-committed ones. 
The literature support the positive relationship referring that job crafting is an effective model of intervention in workplace as it demand an active role in work (Slemp et al., 2015). They also recognise that, even when employees are not able to redesign their jobs, there are opportunities in the workplace where employees can initiate changes in tasks, interactions or even alter thoughts about their work in such a way to make it more comfortable. Harter et al. (2003) and Warr (1999) report workplace well-being is recognised as a fundamental element of successful organizations, contributing to desirable results such as job retention and better performance, and consequently, more productivity.

On another hand, over-commitment patterns should be detected and managed in time; education on the matter, especially given the non-consciousness on the phenomenon described as typical in those who experience it, is necessary. Additionally, certain demographical characteristics have been found to be predictive of differences in the way it impacts on workers. Siegrist et al. (2004), have indicated that females, and also higher educational levels seem to predict higher levels of over-commitment. Aging, on the contrary, doesn't modify this effect significantly, but younger employees report higher levels of over-commitment whilst older workers report lesser perceived levels of effort and higher perceived levels of reward. After the 40-45 years of age peak range, perceived over-commitment seems to decrease, and it has been stated that it could be given to the fact that older employees near to their retirement develop stronger desires of paying attention to loved ones and the establishment of relationships with them instead of allocating attention to imbalanced life experiences that entail disappointment (Fernández-López et al., 2005; Siegrist et al., 2004; Topa et al., 2016).

In the Southern European context, and specially in Spain, one of the most affected countries in terms of job offer by the consequences of the economic crisis from the late 2000s, studies have supported the predominance of over-commitment patterns in women, with a marked tendency in higher educational levels, dedicated to white collar activities, with ages spanning from 40 to 45 years old (and up to 54 years of age, according to Macías et al., 2003), and higher positions in organizational structures, exactly as those found in other latitudes when studying the variable (Fernández-López et al., 2005; Topa et al., 2016). In this sense, it is necessary to be sensitive to age and gender diversity when designing intervention and training programs 
to reduce over-commitment.

Simultaneously, adequate personnel retention strategies could be put into practice, to cushion the crisis contraction impact, and the voluntary enrollment in over-commitment patterns possibly arising; creative compensation figures could be developed, along strong identification links with the employees, to demonstrate interest to retain personnel and proving care for the workforce despite the economic contraction.

\section{Funding}

The author(s) received no financial support for the research, authorship, and/or publication of this article. 


\section{References}

Allisey, A., Rodwell, J. and Noblet, A. (2016), “An application of an extended Effort-Reward Imbalance model to police absenteeism behavior". Personnel Review, Vol. 45 No. 4, pp. 663-680.

Associació Catalana de Recursos Assistencials (ACRA). (2014), "Informe econòmic i social ACRA del sector d'atenció a les persones grans amb dependencia a Catalunya. Serveis Residencials i d'Atenció

Diürna. Serveis d'Atenció Domiciliària”, available at http://itemsweb.esade.edu/idgp/Presentacio_2014_InformeEconomicACRA.pdf $\quad$ (accessed 10 January 2017).

Bakker, A. B. (2015), “Towards a multilevel approach of employee well-being”, European Journal of Work and Organizational Psychology, Vol. 24 No. 6, 839-843.

Bakker, A. B. and Costa, P. L. (2014), "Chronic job burnout and daily functioning: A theoretical analysis", Burnout Research, Vol. 1 No. 3, pp. 112-119.

Berg, J. M., Dutton, J. E. and Wrzesniewski, A. (2008), "What is job crafting and why does it matter?", Regents of the University of Michigan, available at: Website of the Center for Positive Organizational Scholarship of the University of Michigan: http://positiveorgs.bus.umich.edu/wpcontent/uploads/What-is-Job-Crafting-and-Why-Does-it-Matter1.pdf $\backslash$ (accessed on 22 January 2016)

Berg, J. M., Dutton, J. E. and Wrzesniewski, A. (2013), “Job crafting and meaningful work”, in Dik, B. J., Byrne, Z. S. and Steger, M. F. (Eds.), Purpose and meaning in the workplace, American Psychological Association, Washington D.C., D.C., pp. 81-104.

Berg, J. M., Grant, A. M. and Johnson, V. (2010), "When callings are calling: Crafting work and leisure in pursuit of unanswered occupational callings”, Organization Science, Vol. 21 No. 5, pp. 973-994.

Chen, S. (2016), "Effort- Imbalance, overcommitment, perceived control and health behaviours in Central and Eastern Europe" (Doctoral dissertation), University College Reward of London, London, United Kingdom.

Chung, W. C., Yang, S. C., Chiou, W. B. and Tzeng, D. S. (2015), "Effort Reward Imbalance for 
psychological morbidity among first year postgraduate residents", Journal of Psychiatry, Vol. 18 No. 2, pp. 1-7.

Córdoba-Doña, J. A., Escolar-Pujolar, A., San Sebastián, M. and Gustafsson, P. E. (2016), "How are the employed and unemployed affected by the economic crisis in Spain? Educational inequalities, life conditions and mental health in a context of high unemployment", BMC Public Health, Vol. 16 No. 1, p. 267.

Demerouti, E. and Bakker, A. (2014), "Job crafting”, in Peeters, M., De Jonge, J. and Taris, T. (Eds.), An introduction to contemporary work psychology, John Wiley \& Sons, San Francisco, CA, pp. 414433.

Fernández-López, J. A., Fernández-Fidalgo, E. and Siegrist, J. (2005), “El trabajo y sus repercusiones en la salud. El modelo "Desequilibrio Esfuerzo-Recompensa-DER"”, Revista de Calidad Asistencial, Vol. 20 No. 3, pp. 165-170.

Feuerhahn, N., Kühnel, J., and Kudielka, B. M. (2012), "Interaction effects of effort-reward imbalance and overcommitment on emotional exhaustion and job performance", International Journal of Stress Management, Vol. 19 No. 2, pp. 105-131. doi: 10.1037/a0028338

French, M. (2009), “Job crafting”, in Watkins, R. and Leigh, D. (Eds.), Handbook of improving performance in the workplace. Volume 2: Selecting and implementing performance interventions, John Wiley \& Sons. San Francisco, CA, pp. 555-568.

Ghitulescu, B. E. (2006), "Shaping tasks and relationships at work: Examining the antecedents and consequences of employee job crafting" (Doctoral dissertation), University of Pittsburgh, Pittsburgh, PA.

Goldberg, D. P. (1972), The detection of Psychiatric Illness by Questionnaire: A Technique for the Identification and Assessment of Non-psychotic Psychiatric Illness, Oxford University Press, Oxford, United Kingdom.

Goldberg, D. and Williams, P. (1996), "Cuestionario de Salud General GHQ (General Health Questionnaire): Guía para el usuario de las distintas versions", translated by Lobo, A. and Muñoz, P. 
Masson, S.A, Barcelona, Spain.

Hambleton, R. K. (2004), "Theory, methods, and practices in testing for the 21st century”, Psicothema, Vol. 16 No.4, pp. 696-701.

Harter J. K., Schmidt F. L. and Keyes, C. (2003), "Well-being in the workplace and its relationship to business outcomes: a review of the Gallup studies", in Keyes, C. L. and Haidt, J. (Eds), Flourishing: the positive person and the good life, American Psychological Association: Henkel, Washington, DC, pp. 205-224.

Hayes, A. F. (2013), Introduction to mediation, moderation, and conditional process analysis: A regressionbased approach, Guilford Press, New York, NY.

Huyghebaert, T., Gillet, N., Beltou, N., Tellier, F., and Fouquereau, E. (2018), "Effects of workload on teachers' functioning: a moderated mediation model iincluding sleeping problems and overcommitment", Stress and Health, on-line first, pp. 1-11. doi:10.1002/smi.2820

Instituto Nacional de Estadística (2018), "Encuesta de Población Activa. Primer trimestre de 2018”, available at: http://www.ine.es/daco/daco42/daco4211/epa0118.pdf (accessed on 13 July 2018).

International Test Commission. (2005), "ITC guidelines for translating and adapting tests", available at http://www.intestcom.org/files/guideline_test_adaptation.pdf (accessed 10 November 2016).

Kiefer, T., Hartley, J., Conway, N. and Briner, R. B. (2014), 'Feeling the squeeze: Public employees' experiences of cutback-and innovation-related organizational changes following a national announcement of budget reductions", Journal of Public Administration Research and Theory, Vol. 25 No. 4, pp. 1279-1305.

Kinman, G. (2016), "Effort-reward imbalance and overcommitment in UK academics: implications for mental health, satisfaction and retention", Journal of Higher Education Policy and Management, Vol. 38 No.5, pp. 504-518.

Kinman, G. and Jones, F. (2008), "Effort-Reward Imbalance and overcommitment: Predicting strain in academic employees in the United Kingdom”, International Journal of Stress Management, Vol. 15 No. 4, pp. 381-395. 
László, K. D., Pikhart, H., Kopp, M. S., Bobak, M., Pajak, A., Malyutina, S. et al. (2010) “Job insecurity and health: A study of 16 European countries", Social Science \& Medicine, Vol. 70 No. 6, pp. 867874.

Lehr, D., Koch, S. and Hillert, A. (2010), "Where is (im)balance? Necessity and construction of evaluated cut-off points for Effort-Reward Imbalance and overcommitment", Journal of Occupational and Organizational Psychology, Vol. 83 No. 1, pp. 251-261.

Lu, C. Q., Wang, H. J., Lu, J. J., Du, D. Y. and Bakker, A. B. (2014), "Does work engagement increase person-job fit? The role of job crafting and job insecurity", Journal of Vocational Behavior, Vol. 84 No. 2, pp. 142-152.

Lunau, T., Wahrendorf, M., Dragano, N. and Siegrist, J. (2013), "Work stress and depressive symptoms in older employees: Impact of national labour and social policies”, BMC Public Health, Vol. 13 No. 1086, pp.1-10.

Macías, M., Fernández-López, J. A., Hernández-Mejía, R., Cueto-Espinar, A., Rancaño, I. and Siegrist, J. (2003), “Evaluación del estrés laboral en trabajadores de un hospital público Español. Estudio de las propiedades psicométricas de la versión Española del modelo «Desequilibrio EsfuerzoRecompensa»", Medicina Clínica (Barc), Vol. 120 No. 17, pp. 652-657.

Niessen, C., Weseler, D., Kostova, P. (2016), "When and why do individuals craft their jobs? The role of individual motivation and work characteristics for job crafting”, Human Relations, Vol. 69 No. 6, pp. 1287-1313.

Peiró, J. M., Ayala, Y., Tordera, N., Lorente, L. and Rodríguez, I. (2014), "Sustainable well-being at work: A review and reformulation", Papeles del Psicólogo, Vol. 35 No.1, pp. 5-14.

Petrou, P., Demerouti, E. and Schaufeli, W. B. (2016), "Crafting the change: The role of employee job crafting behaviors for successful organizational change", Journal of Management, Vol. 20 No. 10, pp. 1-27.

Petrou, P., Demerouti, E. and Xanthopoulou, D. (2016), "Regular versus cutback-related change: The role of employee job crafting in organizational change contexts of different nature", International Journal 
of Stress Management, Vol. 24 No. 1, pp. 1-24.

Philp, M., Egan, S. and Kane, R. (2012), "Perfectionism, over commitment to work, and burnout in employees seeking workplace counselling”, Australian Journal of Psychology, Vol. 64 No. 2, pp. 6874.

Reimann, M. (2016), “The moderating role of overcommitment in the relationship between psychological contract breach and employee mental health", Journal of Occupational Health, Vol. 58 No. 5, pp. 425-433. doi:10.1539/joh.16-0032-OA

Rennesund, Å. B. and Saksvik, P. Ø. (2010), "Work performance norms and organizational efficacy as cross-level effects on the relationship between individual perceptions of self-efficacy, overcommitment, and work-related stress", European Journal of Work and Organizational Psychology, Vol. 19 No. 6, pp. 629-653.

Rocha, K. B., Pérez, K., Rodríguez-Sanz, M., Borrell, C. and Obiols, J. (2011), "Propiedades psicométricas y valores normativos del General Health Questionnaire (GHQ-12) en población general Española [Psychometric properties and normative values of the General Health Questionnaire (GHQ-12) in the Spanish general population”, International Journal of Clinical and Health Psychology, Vol. 11 No. 1, pp. 125-139.

Sánchez-López, M. and Dresch, V. (2008), “The 12-Item General Health Questionnaire (GHQ-12): Reliability, external validity and factor structure in the Spanish population”, Psicothema, Vol. 20 No. 4, pp. 839-843.

Schweder, P., Quinlan, M., Bohle, P., Lamm, F. and Ang, A. H. (2015), “Injury rates and psychological wellbeing in temporary work: A study of seasonal workers in the New Zealand food processing industry", New Zealand Journal of Employment Relations, Vol. 40 No. 2, pp. 24-51.

Siegrist, J. (1996), “Adverse health effects of high-effort/low-reward conditions”, Journal of Occupational Health Psychology, Vol. 1 No. 1, pp. 27-41.

Siegrist, J. (2001), “A theory of occupational stress", in Dunham, J. (Ed.), Stress in the workplace: Past, present and future, Whurr Publishers, London, pp. 1-16. 
Siegrist, J. (2002), "Effort-Reward Imbalance at work and health", in Perrewe, P. and Ganster, D. (Eds.), Research in occupational stress and well being: Historical and current perspectives on stress and health, Elsevier, New York, NY, pp. 261-291.

Siegrist, J. and Li, J. (2016), “Associations of extrinsic and intrinsic components of work stress with health: A systematic review of evidence on the Effort-Reward Imbalance model", International Journal of Environmental Research and Public Health, Vol. 13 No. 432, pp. 1-14.

Siegrist, J., Starke, D., Chandola, T., Godin, I., Marmot, M., Niedhammer, I. et al. (2004), “The measurement of Effort-Reward Imbalance at work: European comparisons", Social Science \& Medicine, Vol. 58 No. 8, pp. 1483-1499.

Siegrist, J., Wege, N., Pühlhofer, F. and Wahrendorf, M. (2009), "A short generic measure of work stress in the era of globalization: Effort-Reward Imbalance", International Archives of Occupational and Environmental Health, Vol. 82 No. 8, pp. 1005-1013.

Slemp, G. R. and Vella-Brodrick, D. A. (2013), “The Job Crafting Questionnaire: A new scale to measure the extent to which employees engage in job crafting”, International Journal of Wellbeing, Vol. 3 No. 2, pp. 126-146.

Slemp, G. R. Kern, M. L. and Vella-Brodrick, D. A. (2015), "Workplace Well Being: The Role of Job Crafting and Autonomy Support”, Psychological Well-Being, Vol. 5 No. 7, pp. 1-17.

Tims, M., Bakker, A. B. and Derks, D. (2013), "The Impact of job crafting on job demands, job resources, and well-being”, Journal of Occupational Health Psychology, Vol. 18 No. 2, pp. 230-240.

Topa, G., Guglielmi, D. and Depolo, M. (2016), "Effort-Reward Imbalance and organisational injustice among aged nurses: A moderated mediation model”, Journal of Nursing Management, Vol. 24 No. 6, pp. 834-842.

Urbanos-Garrido, R. M. and Lopez-Valcarcel, B. G. (2014), “The influence of the economic crisis on the association between unemployment and health: An empirical analysis for Spain", The European Journal of Health Economics, Vol. 16 No. 2, pp. 175-184.

Van Vegchel, N., De Jonge, J., Bosma, H. and Schaufeli, W (2005), "Reviewing the Effort-Reward 
Imbalance model: Drawing up the balance of 45 empirical studies”, Social \& Science Medicine, Vol. 60 No. 5, pp. 1117-1131.

Warr, P. B. (1999), "Well-being and the workplace”, in Kahneman, D., Diener, E. and Schwarz, N. (Eds.), Well-being: the foundations of hedonic psychology, Russell Sage, New York, pp. 392-412.

Wrzesniewski, A., Berg, J. M. and Dutton, J. E. (2010), “Turn the job you have into the job you want", Harvard Business Review, Vol. 88 No.6, pp. 114-117.

Wrzesniewski, A. and Dutton, J. E. (2001), "Crafting a job: Revisioning employees as active crafters of their work", Academy of Management Review, Vol. 26 No. 2, pp. 179-201.

Wrzesniewski, A., LoBuglio, N., Dutton, J. E. and Berg, J. M. (2013), “Job crafting and cultivating positive meaning and identity in work", in Bakker, A. (Ed.), Advances in Positive Organizational Psychology, Emerald Group Publishing Limited, Bingley, United Kingdom, pp. 281-302.

Yepes-Baldó, M., Romeo, M., Westerberg, K. and Nordin, M. (2016), “Job crafting, employee well-being, and quality of care", Western Journal of Nursing Research, pp. 1-15. 
Table 1

Sample's Description

\begin{tabular}{lll}
\hline \multicolumn{2}{c}{ Variable } & Descriptives \\
\hline \multirow{2}{*}{ Age } & & $\begin{array}{l}M=44.62 \text { years old, } S D=11.28 \text { y/o. } \\
\text { Minimum 19 y/o. - Maximum 63 y/o. }\end{array}$ \\
\hline \multirow{2}{*}{ Gender } & Male & $\mathrm{n}=41(11.6 \%)$ \\
& Female & $\mathrm{n}=299(84.7 \%)$ \\
\multirow{2}{*}{ Job Position } & Operative & $\mathrm{n}=256(72.5 \%)$ \\
& Managerial & $\mathrm{n}=46(13 \%)$ \\
\multirow{2}{*}{ Type of Contract } & Temporary & $\mathrm{n}=46(13 \%)$ \\
& Permanent & $\mathrm{n}=287(81.30 \%)$ \\
\multirow{2}{*}{ Shift } & Day & $\mathrm{n}=261(73.9 \%)$ \\
& Night & $\mathrm{n}=24(6.8 \%)$ \\
\hline
\end{tabular}

Table 2

Estimates after Confirmatory Factor Analysis of the Over-commitment Scale Administration to a Spanish Sample

\begin{tabular}{|c|c|c|c|}
\hline $\begin{array}{ll}\text { Item } \\
\end{array}$ & Estimation & Measurement Error & $\boldsymbol{R}^{2}$ \\
\hline $\begin{array}{l}\text { 1. Me siento fácilmente abrumado por las presiones de tiempo } \\
\text { en el trabajo [I get easily overwhelmed by time pressures at } \\
\text { work] }\end{array}$ & .400 & .054 & .160 \\
\hline $\begin{array}{l}\text { 2. Tan pronto como me levanto por la mañana empiezo a } \\
\text { pensar en problemas de trabajo [As soon as I get up in time } \\
\text { morning I start thinking about work problems] }\end{array}$ & .782 & .054 & .611 \\
\hline $\begin{array}{l}\text { 3. Cuando llego a casa, me puedo relajar fácilmente } \\
\text { y 'desconectar' del trabajo [When I get home, I can easily relax } \\
\text { and 'switch off' work] }\end{array}$ & .620 & .055 & .384 \\
\hline $\begin{array}{l}\text { 4. Personas cercanas a mí me dicen que sacrifico demasiado } \\
\text { por mi trabajo [People close to me say I sacrifice too much for } \\
\text { my job] }\end{array}$ & .566 & .067 & .320 \\
\hline $\begin{array}{l}\text { 5. Mi trabajo sigue estando en mi cabeza cuando me voy a la } \\
\text { cama [Work rarely lets me go, it is still on my mind when I go } \\
\text { to bed] }\end{array}$ & .824 & .048 & .679 \\
\hline $\begin{array}{l}\text { 6. Cuando aplazo algo que se suponía que debía hacer hoy } \\
\text { tengo problemas para dormir por la noche [If I postpone } \\
\text { something that I was supposed to do today I'll have trouble } \\
\text { sleeping at night] }\end{array}$ & .705 & .056 & .479 \\
\hline
\end{tabular}


Table 3

Descriptive Statistics, Internal Consistency, Cronbach's Alpha and Correlations amongst Variables

\begin{tabular}{lccccccccc}
\hline Scale & Min & Max & M & SD & $\mathbf{1}$ & $\mathbf{2}$ & $\mathbf{3}$ & $\mathbf{4}$ & $\mathbf{5}$ \\
\hline 1. Task Job crafting & 1.00 & 5.00 & 3.13 & .873 & .786 & & & & \\
2. Cognitive Job crafting & 1.00 & 5.00 & 3.47 & .846 & $.508^{* *}$ & .793 & & & \\
3. Relational Job crafting & 1.00 & 5.00 & 3.10 & .856 & $.432^{* *}$ & $.429^{* *}$ & .708 & & \\
4. Well-being & 1.50 & 3.92 & 3.21 & .378 & $.199^{* *}$ & $.236^{* *}$ & $.169^{* *}$ & .863 & \\
5. Over-commitment & 1.00 & 5.00 & 2.49 & .781 & .057 & .032 & .073 & $-.519^{* *}$ & .814 \\
\hline
\end{tabular}

Note: Cronbach's Alpha on main diagonal; **. Correlation is significant at the .01 level (2-tailed).

Table 4

Simple Regression Analyses of Relationship amongst Job Crafting and Well-being

\begin{tabular}{lccccc}
\hline \multicolumn{5}{c}{ Well-being } & \multicolumn{2}{c}{} \\
\hline Dimension & $\boldsymbol{B}$ & $\boldsymbol{\beta}$ & $\boldsymbol{t}$ & $\mathrm{R}^{2}$ & \multicolumn{1}{c}{$\boldsymbol{F}$} \\
\hline Task crafting & .086 & $.199^{*}$ & 3.770 & .040 & $14.216^{*}$ \\
Cognitive crafting & .105 & $.236^{*}$ & 4.552 & .056 & $20.718^{*}$ \\
Relational crafting & .075 & $.169^{*}$ & 3.203 & .029 & $10.262^{*}$ \\
\hline
\end{tabular}

$* p \leq .001$.

Table 5

Over-commitment Moderation Effect in the Job Crafting - Well-being Relationship

\begin{tabular}{|c|c|c|c|c|c|c|c|c|c|c|}
\hline & \multicolumn{4}{|c|}{ Model Summaries } & \multirow{2}{*}{ Coefficient } & \multicolumn{5}{|c|}{ Sub-dimension Specifics } \\
\hline & $\overline{\mathbf{R}^{2}}$ & $F$ & $\Delta R^{2}$ & $F \Delta$ & & $\boldsymbol{B}$ & $S E B$ & C.I. & $t$ & $p$ \\
\hline \multirow{3}{*}{$\begin{array}{l}\text { Task } \\
\text { Crafting }\end{array}$} & \multirow{3}{*}{.3320} & \multirow{3}{*}{$56.152^{* * *}$} & \multirow{3}{*}{.0156} & \multirow{3}{*}{$7.928^{*}$} & b1 & -.059 & .074 & $-.178, .059$ & -.988 & .3237 \\
\hline & & & & & b2 & -.457 & .060 & $-.603,-.310$ & -6.148 & $<.001$ \\
\hline & & & & & b3 & .065 & .0234 & $.019, .112$ & 2.815 & .005 \\
\hline \multirow{3}{*}{$\begin{array}{l}\text { Cognitive } \\
\text { Crafting }\end{array}$} & \multirow{3}{*}{.3351} & \multirow{3}{*}{$57.796^{* *}$} & \multirow{3}{*}{.0001} & \multirow{3}{*}{.0714} & b1 & .103 & .061 & $-.016, .223$ & 1.693 & .091 \\
\hline & & & & & b2 & -.275 & .082 & $-.439,-.112$ & -3.325 & .001 \\
\hline & & & & & b3 & .006 & .023 & $-.039, .051$ & .2672 & .789 \\
\hline \multirow{3}{*}{$\begin{array}{l}\text { Relational } \\
\text { Crafting }\end{array}$} & \multirow{3}{*}{.3322} & \multirow{3}{*}{$56.697^{* *}$} & \multirow{3}{*}{.0209} & \multirow{3}{*}{$10.716^{*}$} & b1 & -.112 & .065 & $-.241, .016$ & -1.710 & .088 \\
\hline & & & & & b2 & -.504 & .078 & $-.658,-.350$ & -6.461 & .000 \\
\hline & & & & & b3 & .079 & .024 & $.031, .126$ & .3 .273 & .001 \\
\hline
\end{tabular}

$* p<.01, * * p<.001$ 


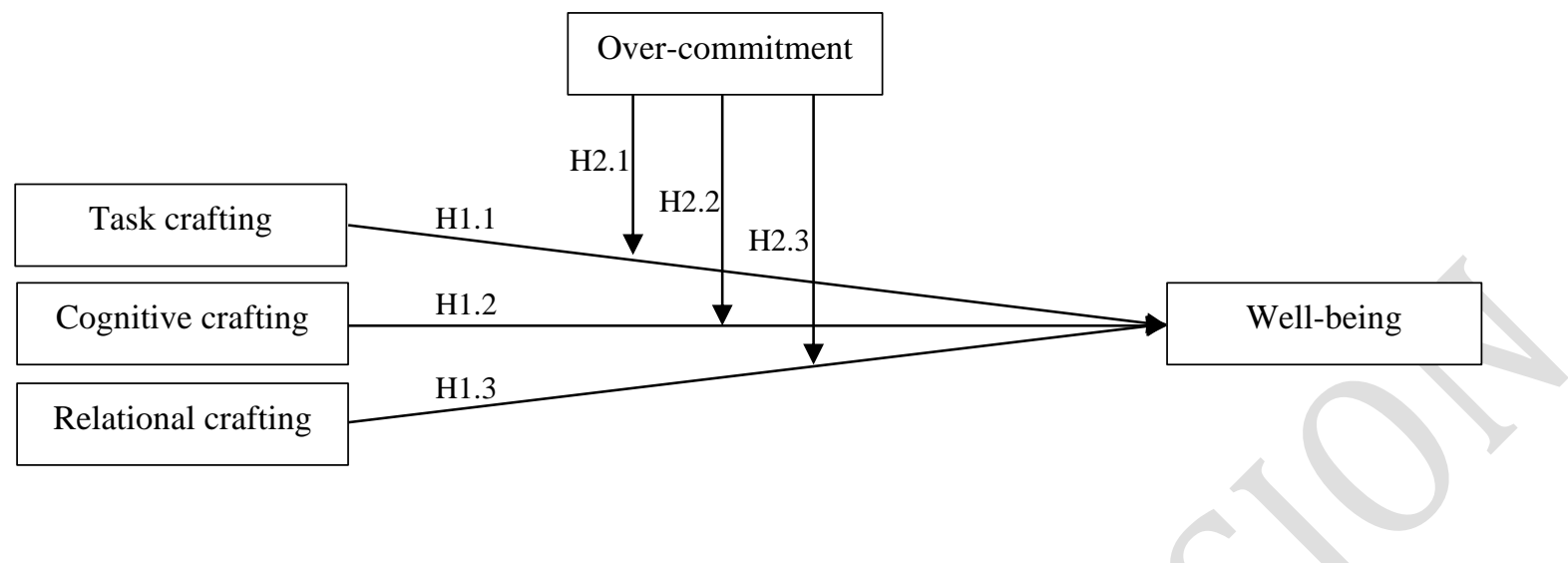

Figure 1. Proposed effects between job crafting (and its sub-dimensions) and well-being as moderated by over-commitment. 


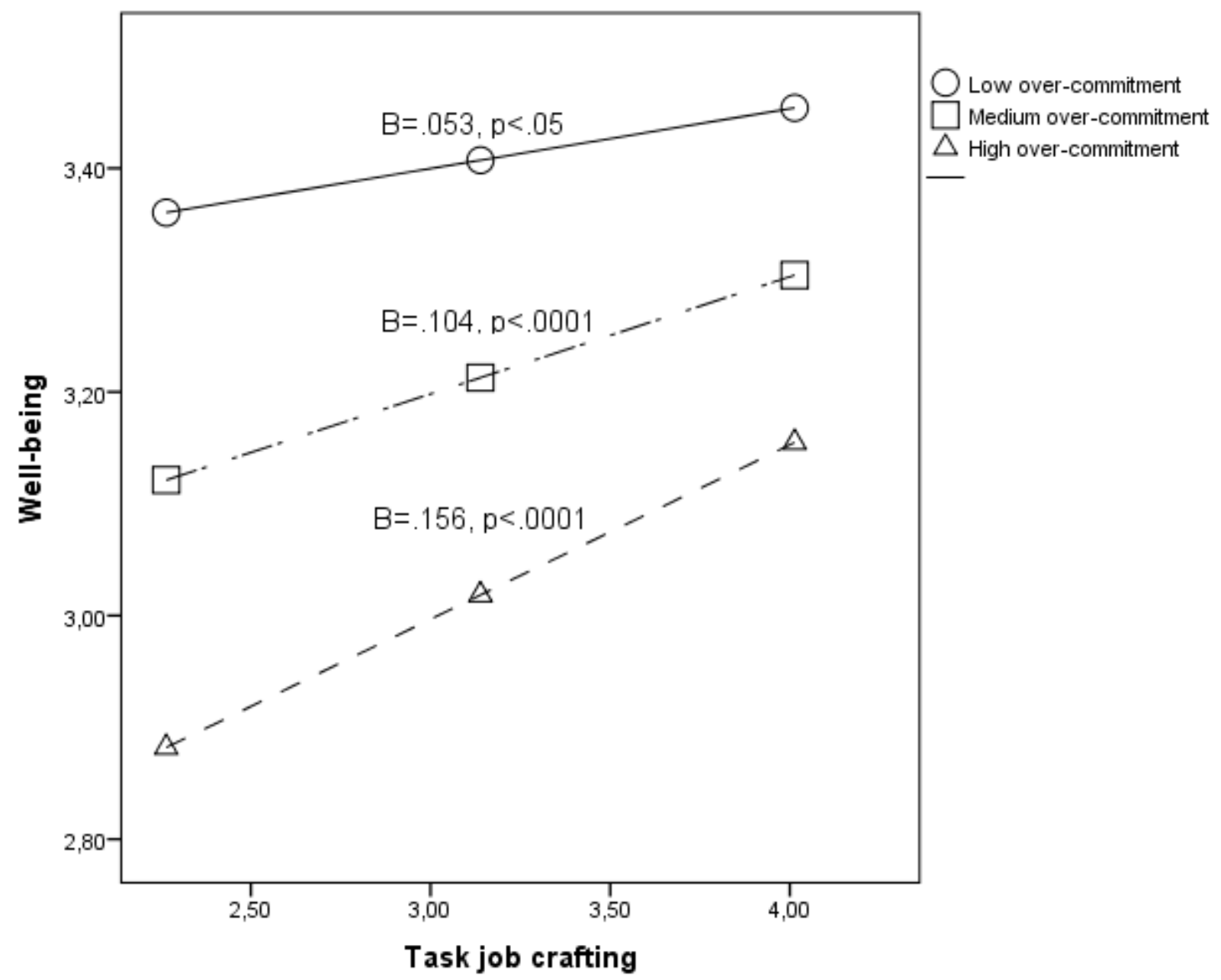

Figure 2. Simple Slopes of Task Job Crafting Predicting Well-being for $1 S D$ Below, 1 SD Above, and Properly in the Mean of Over-commitment. Note: B = Conditional effect (non-standardized beta) of X on $\mathrm{Y}$ at values of the moderator $(\mathrm{M})$ 


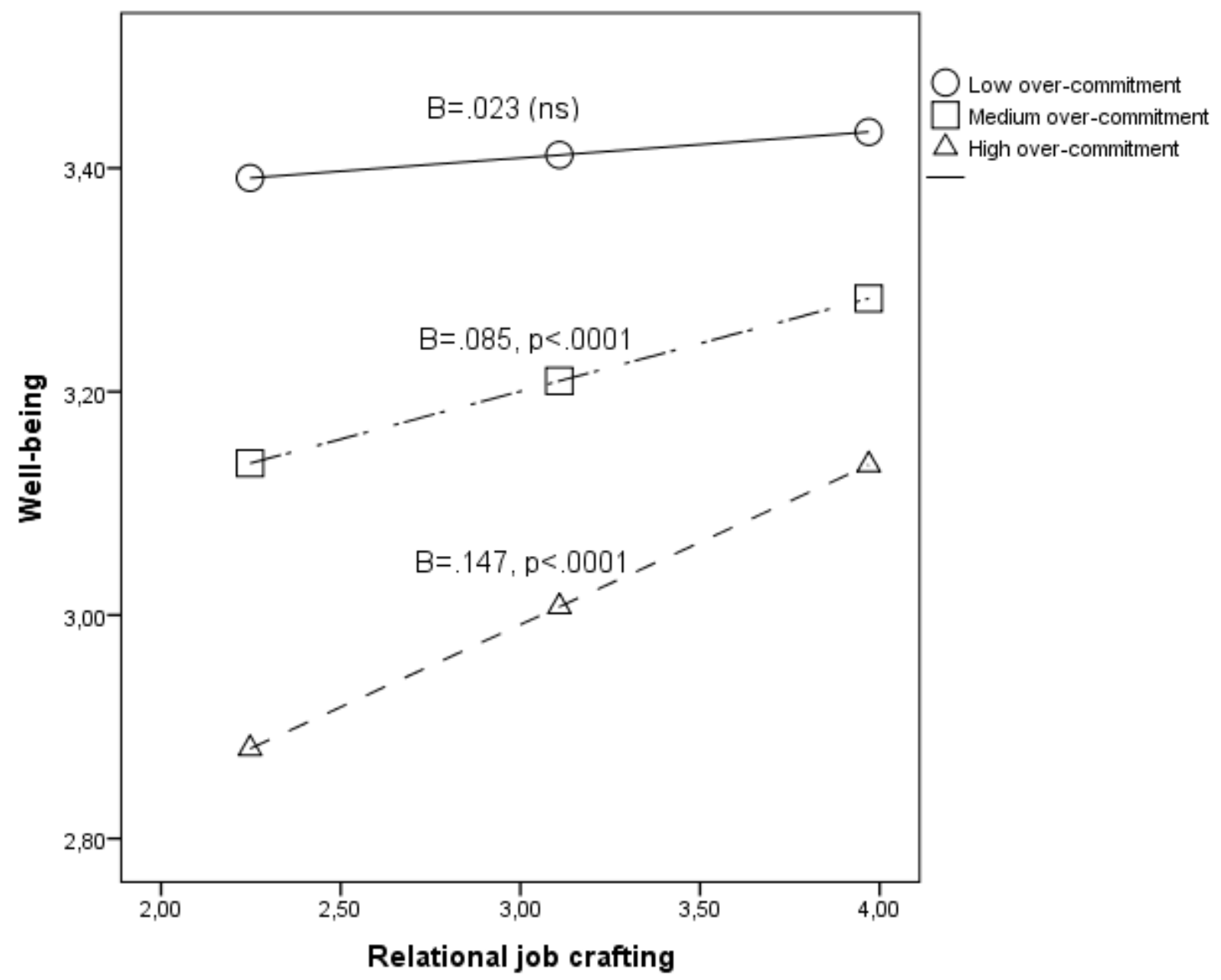

Figure 3. Simple Slopes of Relational Job Crafting Predicting Well-being for $1 S D$ Below, 1 SD Above, and Properly in the Mean of Over-commitment. Note: B = Conditional effect (non-standardized beta) of X on $\mathrm{Y}$ at values of the moderator $(\mathrm{M})$ 